\title{
DIRECT AND INVERSE APPROXIMATION THEOREMS OF FUNCTIONS IN THE MUSIELAK-ORLICZ TYPE SPACES
}

\section{FAHreddin AbDullayeV*, Stanislav Chaichenko AND ANDRII Shidlich}

Abstract. In Musilak-Orlicz type spaces $\mathscr{S}_{\mathbf{M}}$, direct and inverse approximation theorems are obtained in terms of the best approximations of functions and generalized moduli of smoothness. The question of the exact constants in Jackson-type inequalities is studied.

Mathematics subject classification (2010): 41A27, 42A16, 41A44.

Keywords and phrases: Direct approximation theorem, inverse approximation theorem, generalized modulus of smoothness, best approximation, Musilak-Orlicz type spaces.

\section{REFERENCES}

[1] F. Abdullayev, S. Chaichenko, M. Imash Kyzy, A. Shidlich, Direct and inverse approximation theorems in the weighted Orlicz-type spaces with a variable exponent, Turk. J. Math., 44 (2020), 284-299.

[2] F. G. Abdullayev, P. ÖZkartepe, V. V. Savchuk, A. L. Shidlich, Exact constants in direct and inverse approximation theorems for functions of several variables in the spaces $\mathscr{S}^{p}$, Filomat, $\mathbf{3 3}$, 5 (2019), 1471-1484.

[3] R. AKGÜN, Y. YILDIRIR, Jackson-Stechkin type inequality in weighted Lorentz spaces, Math. Inequal. Appl., 18 (2015), 1283-1293.

[4] R. AKGÜN, V. KoKILASHVILI The refined direct and converse inequalities of trigonometric approximation in weighted variable exponent Lebesgue spaces, Georgian Math. J., 18 (2011), 399-423.

[5] A. G. BABenKo, On exact constant in the Jackson inequality in $L_{2}$, Math. Notes, 39, 5 (1986), 355363.

[6] N. K. BARI, S. B. STEChKIn, Best approximations and differential properties of two conjugate functions, Trudy Moskov. Mat. Obsch., 5 (1956), 483-522 [in Russian].

[7] S. N. BERNSTEIN, On the best approximation of continuous functions by polynomials of given degree (1912), in: Collected Works, 1, Acad. Nauk SSSR, Moscow, 11-104 (1952) [in Russian].

[8] J. Boman, H. S. Shapiro, Comparison theorems for a generalized modulus of continuity, Ark. Mat., 9(1971), 91-116.

[9] J. Boman, Equivalence of generalized moduli of continuity, Ark. Mat., 18 (1980), 73-100.

[10] P. Butzer, R. Nessel, Fourier Analysis and Approximation. One-Dimensional Theory, Birkhäuser, Basel, 1971.

[11] S. Chaichenko, A. Shidlich, F. Abdullayev, Direct and inverse approximation theorems of functions in the Orlicz type spaces $\mathscr{S}_{M}$, Math. Slovaca, 69, 6 (2019), 1367-1380.

[12] N. I. CHERNY KH, On the Jackson inequality in $L_{2}$, Tr. Mat. Inst. Akad. Nauk SSSR, 88 (1967), 71-74 [in Russian].

[13] N. I. CHERNYKH, On the best approximation of periodic functions by trigonometric polynomials in $L_{2}$, Mat. Zametki, 20, 3 (1967), 513-522 [in Russian].

[14] R. A. DeVore, G. G. Lorentz, Constructive Approximation, Springer, Berlin, 1993.

[15] V. K. DZYADYK, I. A. SHEvChUK, Theory of uniform approximation of functions by polynomials, Walter de Gruyter GmbH \& Co. KG, Berlin, 2008.

[16] A. Guven, D. IsRAFILOV, Trigonometric approximation in generalized Lebesgue spaces $L^{p(x)} \mathrm{J}$. Math. Inequal., 4 (2010), 285-299.

[17] G. H. Hardy, J. E. Littlewood, G. Pólya, Inequalities, Cambridge University Press, 1934. 
[18] D. JACKSON, Über die Genauigkeit der Annäherung stetiger Funktionen durch ganze rationale Funktionen gegebenen Grades und trigonometrische Summen gegebener Ordnung, Göttingen, 1911, Thesis.

[19] S. Z. JAFAROv, The inverse theorem of approximation of the function in Smirnov-Orlicz classes, Math. Inequal. Appl., 12, 4 (2012), 835-844.

[20] S. Z. JAFAROV, Approximation of conjugate functions by trigonometric polynomials in weighted Orlicz spaces, J. Math. Inequal., 7, 2 (2013), 271-281.

[21] N. KorneichuK, Exact constants in approximation theory, Transl. from the Russian by K. Ivanov. Reprint of the hardback edition 1991. Encyclopedia of Mathematics and its Applications, 38, Cambridge: Cambridge University Press.

[22] A. I. Kozko, A. V. RozhdeSTVEnskiI, On Jackson's inequality for a generalized modulus of continuity in $L_{2}$, Sb. Math., 195, 8 (2004), 1073-1115.

[23] J. Lindenstrauss, L. TZAFriri, Classical Banach spaces I: Sequence Spaces, Berlin, 1977.

[24] J. MusielaK, Orlicz Spaces and Modular Spaces, Springer, Berlin, 1983.

[25] H. S. SHAPIRO, A Tauberian theorem related to approximation theory, Acta Math., 120 (1968), 279 292.

[26] I. I. SHARAPUDINOV On direct and inverse theorems of approximation theory in variable Lebesgue and Sobolev spaces, Azerbaijan Journal of Mathematics, 4, 1 (2014), 55-72.

[27] A. I. Stepanets, Approximation characteristics of the spaces $\mathscr{S}_{\varphi}^{p}$, Ukrainian Math. J., 53, 3 (2001), 446-475.

[28] A. I. StePanets, Methods of Approximation Theory, VSP, Leiden-Boston, 2005.

[29] A. I. STEPANETS, A. S. SERDYUK, Direct and inverse theorems in the theory of the approximation of functions in the space $\mathscr{S}^{p}$, Ukrainian Math. J., 54, 1 (2002), 126-148.

[30] M.D. STERLIN, Exact constants in inverse theorems of approximation theory, Dokl. Akad. Nauk SSSR, 202 (1972), 545-547 [in Russian].

[31] A. F. Timan, Theory of approximation of functions of a real variable, Fizmatgiz, Moscow, 1960 [in Russian]; English translation by J. Berry, International Series of Monographs on Pure and Applied Mathematics 34, Pergamon Press and MacMillan, Oxford, 1963.

[32] M. F. Timan, Approximation and properties of periodic functions, Nauk. dumka, Kiev, 2009 [in Russian].

[33] S. B. VAKARCHUK, Jackson-type inequalities and exact values of widths of classes of functions in the spaces $S^{p}, 1 \leqslant p<\infty$, Ukrainian Math. J., 56, 5 (2004), 718-729.

[34] S. B. VAKARChUK, A. N. ShChitov, On some extremal problems in the theory of approximation of functions in the spaces $S^{p}, 1 \leqslant p<\infty$, Ukrainian Math. J., 58, 3 (2006), 340-356.

[35] S. B. VAKARCHUK, Jackson-type inequalities with generalized modulus of continuity and exact values of the $n$-widths of the classes of $(\psi, \beta)$-differential functions in $L_{2}, I$, Ukrainian Math. J., 68, 6 (2016), $823-848$.

[36] S. N. VASIL'Ev, The Jackson-Stechkin inequality in $L_{2}[-\pi, \pi]$, Proc. Steklov Inst. Math., Suppl., 1, (2001), S243-S253.

[37] S. N. VASIL'Ev, Jackson inequality in $L_{2}\left(T^{N}\right)$ with generalized modulus of continuity, Proc. Steklov Inst. Math., Suppl., 265, 1, (2009), S218-S226. 